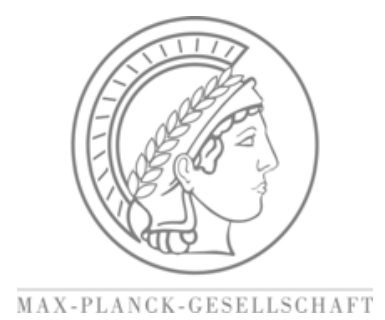

A Corporation's Culture as an Impetus for Spinoffs and a Driving Force of Industry Evolution

by

Christian Cordes Peter J. Richerson Georg Schwesinger

The Papers on Economics and Evolution are edited by the Evolutionary Economics Group, MPI Jena. For editorial correspondence, please contact: evopapers@econ.mpg.de

ISSN 1430-4716
Max Planck Institute of Economics Evolutionary Economics Group Kahlaische Str. 10 07745 Jena, Germany Fax: ++49-3641-686868

(C) by the author 


\title{
A Corporation's Culture as an Impetus for Spinoffs and a Driving Force of Industry Evolution
}

\author{
Christian Cordes, Peter J. Richerson, and Georg Schwesinger
}

August 2011

\begin{abstract}
In infant industries, a great share of new market opportunities is depleted by firms that spinoff from incumbents. A model emphasizing the relation between incumbents' evolving corporate cultures and the generation of spinoffs explains this regularity in industry evolution. Organizations reach a critical size that entails the collapse of a cooperative culture and triggers the exodus of personnel founding own firms. Thereby, organizations with a cooperative culture active in a dynamic business environment provide ideal training grounds for potential founders. We relate our findings to empirical evidence on developmental patterns in industries, such as genealogies and performance of spinoffs.
\end{abstract}

Keywords: Spinoff Formation - Critical Firm Size - Firm Performance - Industry Evolution Corporate Culture

JEL Codes: D21, L25, L26, M13, M14, C61

\footnotetext{
${ }^{*}$ Cordes (corresponding author) and Schwesinger: Max Planck Institute of Economics, Kahlaische Str. 10, 07745 Jena, Germany (e-mail: cordes@econ.mpg.de and schwesinger@econ.mpg.de); Richerson: University of California at Davis, Department of Environmental Science and Policy, One Shields Ave, CA 95616 Davis, USA (e-mail: pjricherson@ucdavis.edu).
} 


\section{Introduction}

This paper relates firms' evolving corporate cultures, firm size, and the generation of spinoffs out of incumbent enterprises. We offer a theory of spinoffs that explains some salient aspects of these important market entrants. Especially, we address the origins of spinoffs' capabilities that prove to be superior to those of other types of entrants by taking a closer look at intraorganizational learning processes (see Klepper and Sleeper, 2005; Buenstorf and Klepper, 2009). A formal model explores how changes in a corporation's evolving culture trigger spinoffs, how parent firm culture affects their performance, and how these developments at the organizational level interact with the evolution of the industry in which the firm is active. By doing so, we capture different patterns in firm development that finally will help explain the evolutionary paths that industries may follow. While many theories of industry evolution highlight the selectionist part of evolution (e.g., Hannan and Freeman, 1977; Jovanovic and MacDonald, 1994), we add an explanation that relies on intraorganizational learning processes.

Entrants of all kinds play an important role in models of industrial competition (e.g., Garvin, 1983; Klepper and Sleeper, 2005). We analyze the origins of some entrants - spinoffs, i.e., entrants founded by employees of firms in the same industry - and how their specific background affects their fates. Spinoffs have begun to receive special attention in the literature in recent years due to their central role in the evolution of a number of new industries and industrial clusters particularly early in their life cycles (for an overview, see Klepper, 2009). This class of market entrants spurred the formation and growth of several well researched industries, such as semiconductors (Brittain and Freeman, 1986), automobiles (Klepper, 2002), biotechnology (Stuart and Sorenson, 2003), tires (Buenstorf and Klepper, 2009), disk drives (Agarwal et al., 2004), lasers (Klepper and Sleeper, 2005), and medical services (Chatterji, 2009).

There are several existing theories of why spinoffs occur. Pakes and Nitzan (1983) offer an approach that relies on a contracting perspective to explain spinoffs, Franco and Filson (2006) argue that employees accept lower wages to work at better firms to attain knowledge they need to start their own firms, Klepper and Sleeper (2005) suggest a Hotelling-like model in which employees develop variants of their parents' products, Cabral and Wang (2009) argue that better firms spawn more and better spinoffs due to the fact that their own superior performance is based on the quality of their employees, and some more recent theories feature firms' difficulty to assess the quality of their employees' ideas (e.g., Klepper and Thompson, 2010). Our analysis of corporations' cultures and spinoff generation crosses several levels of analysis: first, organizational growth in different business environments, second, firms' evolving cultures as a result of collective learning processes in growing enterprises, third, the triggering of spinoffs through changes in a corporation's culture, and, fourth, the relation between firm development and the spinoff-driven evolution of an industry.

In this context, our search for recurrent patterns in firm development, spinoff generation, and industry evolution that are amenable to theoretical analysis is guided by a model of cultural learning within organizations (see Cordes et al., 2008; 2010). It features rapidly growing firms whose success in an innovative business environment is based on a cooperative corporate culture. These organizations then systematically face a growth crisis (see Churchill and Lewis, 1983; Greiner, 1998), which leads to a dwindling of the intraorganizational level of cooperation and the spawning of spinoffs. Moreover, we argue that cooperative firm cultures and processes of "entrepreneurial imprinting" (Higgins, 2005) are important sources of spinoffs' superior capabilities concerning their later market performance. These processes shape the skills and attitudes that allow some employee to become successful entrepreneurs when they leave the original firm (Klepper and Sleeper, 2005). We provide one explanation for the origins of the 
peculiar capabilities of spinoffs and shed some light on the determinants of valuable pre-entry experiences. Finally, we relate these findings to the evolution of industries by showing how in mature business environments another kind of corporate culture can be successful, how spinoff processes can generate genealogies of firm organizations, and how an exploitable business opportunity affects the likelihood of spinoffs to occur in an industry.

The article is organized as follows. The next Section lays out the model of evolving corporate cultures in different business environments and relates this to cognitive dispositions of human agents and systematically appearing firm growth crises that trigger spinoff activity. Section 3 derives predictions from the model, discusses them, and relates these to empirical evidence on spinoff generation, organizational development, and industry evolution. Section 4 concludes.

\section{The model}

We devise our formal model in three steps. First, we capture differential firm performance in different business environments depending on a venture's corporate culture. Second, we propose a detailed description of a firm's evolving culture based on several learning mechanisms. Third, we specify how spinoff activity is systematically triggered by changes in a corporation's culture.

\subsection{Firm success in varying business environments}

Success or failure of firm organizations depends crucially upon their corporate culture and its coevolution with a changing business environment (Deal and Kennedy, 1982; Kotter and Heskett, 1992; Schein, 1992; Teece et al., 1997; Hermalin, 2001; Kosfeld and von Siemens, 2011). We imagine an industry's evolution starting in a nascent stage characterized by a high degree of uncertainty and change. In the course of time and firm growth, the business environment develops toward a higher degree of certainty that enables size-related economies of scale and performance of routine tasks. We therefore differentiate between two business environments that favor different corporate cultures: one based upon cooperation and one relying on monitoring.

(1) In nascent, innovative, and rapidly changing business environments, organizations have to rely on employees' discretionary contributions to flexibly cope with unpredictable opportunity and adversity (Katz, 1964; Tichy, 1983; March, 1991; Gittell, 2000). Such an uncertain environment necessitates employees that do not restrict their contributions exclusively to what is specified in their employment contracts and formal reward schemes, as these future contingencies cannot be fully anticipated (Deckop et al., 1999). The organization must draw on cooperative agents that put the interest of the work unit ahead of their self-interests (Akerlof and Kranton, 2005; Witt, 2007) and that enjoy a high degree of autonomy and discretion to adapt to a dynamic business environment (Barney, 1986; Rob and Zemsky, 2002). ${ }^{1}$ The higher level of responsibility for firm success left to the employees, however, also entails high potential costs of opportunistic behavior. At the same time, a cooperative culture cannot be based on close monitoring to keep in check opportunistic behavior due to employees' high degree of autonomy and the fact that cooperative agents resent being closely monitored (Cooter and Eisenberg, 2001; Enzle and Anderson, 1993; Ghoshal and Moran, 1996). As shown below, small firms or organizational units have comparative advantages at keeping up a high level of intraorganizational cooperation.

(2) In a mature, stable business environment, often occurring later in the evolution of an industry as the rate of technical innovation slows, more traditional mechanisms of coordination, such as rules, routines, and hierarchy are adequate to ensure success of larger firms (e.g.,

\footnotetext{
${ }^{1}$ A critical share of innovative breakthroughs has been made by firms of modest size (e.g., Christensen, 1993).
} 
Thompson, 1967; Crémer, 1993). The emergence of a dominant product design and investments in expensive capital goods for mass production (see Pratten, 1971; Jovanovic and MacDonald, 1994) increase minimum efficient firm size (Klepper, 1996). Due to the high share of routine tasks, employees' performance is easy to observe and control, facilitating the establishment of a more formalized regime of detailed monitoring to prevent opportunistic behavior (Williamson, 2002), which represents another kind of corporate culture. Organizations' competitive advantage then rests more on size-related economies of scale than the extra effort spent by cooperative employees. Hence, in stable business environments, firms requiring low-cost production strategies implement a culture that emphasizes standardization and efficiency instead of flexibility and cooperation, as it is the case in dynamic, innovative environments.

Consequently, one determinant of firm success or failure is its corporate culture in combination with the business environment it is acting in. To capture the evolution of a corporation's culture and its effects on performance and growth, we look at the learning-based transmission of a dichotomous cultural trait within a firm, the variants labeled by $c$ and $o$, where $c$ represents the variant "cooperative behavior" and $o$ the variant "opportunistic behavior". The state of the group is determined by the frequency of employees with the variant $c$, labeled $p$ (the frequency of the opportunistic variant is $1-p$ ). Besides the well established assumption of an inclination toward opportunism in the theory of the firm, we consider a human behavioral disposition for cooperation (see the abundant evidence from game theory and experimental economics, e.g., Rubin, 1982; Güth and van Damme, 1998; Bolton and Ockenfels, 2000; Fehr and Gächter, 2000). Cooperation frequently emerges spontaneously in small- and medium-sized groups (Henrich et al., 2001; Boyd and Richerson, 2002; Richerson and Boyd, 2005). Before moving to the learning dynamics that determine a firm's evolving culture (represented by $p$ ) in the next subsection, we analyze its growth process as an indicator of success given varying shares of opportunistic and cooperative employees in different business environments.

Ventures based on a cooperative culture reap competitive advantages due to the extra effort spent by their employees (see Kosfeld and von Siemens, 2011). We assume that each cooperative employee contributes to a firm's profit an amount measured by $r_{c}$. Each opportunistic agent yields a profit or loss of $r_{o}(n)$, i.e., her contribution depends on the firm's size. $r_{c / o}$ are measured in units of a standard employee wage. Profits resulting from cooperative or opportunistic agents directly translate into new employees, i.e., firm growth. Then, the following recursion gives the firm's size in the next time step, $n^{\prime}$, given that it was $n$ before:

$$
n^{\prime}=p n\left(1+r_{c}\right)+n(1-p)\left(1+r_{o}(n)\right)
$$

The first part of Equation (1), $p n\left(1+r_{c}\right)$, represents the number of cooperative employees times the unit resources needed to sustain their wages plus the profit they make. Furthermore, we allow for an endogenous modification of the loss or profit of opportunistic employees in the course of firm development: $n(1-p)\left(1+r_{o}(n)\right)$ is the aggregate contribution to a firm's growth yielded by opportunistic agents. The following expression captures the relationship between $r_{o}$ and the total number of a firm's employees, $n$ :

$$
r_{o}(n)=-r_{c}+\frac{n}{n_{\text {crit_tech }}+n} 2 r_{c} .
$$


For small organizational sizes, i.e., rather young firms in nascent, dynamic business environments that rely on cooperation, opportunistic agents cause a loss. When the firm reaches a critical technical firm size, $n_{\text {crit_tech }}$, opportunistic employees start to contribute a profit to firm development. This accounts for the possibility that larger firms (1) can realize economies of scale in a later, stable business environment (e.g., Pratten, 1971; Audretsch and Mahmood, 1994) and (2) face a task structure that is characterized by a relatively higher share of easy to observe, routinized exercises enabling the establishment of a monitoring regime to prevent shirking behavior. Both effects compensate for the losses caused by opportunistic agents in smaller firms. For large firms, $r_{o}$ is asymptotically approaching $r_{c}$.

We extend Equation (1) by a logistic expression to relate an individual firm's growth to effects at the industry level. Corporations' development is influenced by an increasing depletion of a given business opportunity by all firms active in an industry (indexed by $i$ ). Organizations compete for this opportunity and the intensity of the competitive process affects their performance. Then, we obtain the following recursion for a firm's growth process in an industry:

$$
n^{\prime}=n+n\left(p\left(1+r_{c}\right)+(1-p)\left(1+r_{o}(n)\right)-1\right)\left(1-\frac{N}{K}\right)-n(S)
$$

From Equation (1) we derive a firm's growth rate (see Appendix A), which gives us the first expression in parentheses following $n$ in Equation (3). Within the second parentheses, $K$ measures the potential of the new business opportunity, while $N=\sum_{i} n_{i}$ sums up all employees in this industry as a measure of overall firm activity and competition. In the industry's beginnings, $K$ is large relative to $N$ implying high potential growth rates for the pioneering firms. Later on, a growing number of firms and employees doing business in an industry entails decreasing growth rates for single organizations due to fiercer intra-industry competition. Business opportunities for incumbents and new firms dry up in the course of market evolution. Below, the term $n(S)$ is used to specify the harm incurred by parent firms due to spinoff activities as measured by a decrease in their number of employees. It may be a single agent or a team of employees that leaves the organization to found an own firm. Furthermore, this expression might capture the harm inflicted on a parent by the exit of a very valuable employee that entails a severe drop in employment.

\subsection{An organization's evolving corporate culture}

We now lay out a formal approach to firms' evolving corporate cultures. Our model of cultural learning accounts for the processes that change the frequencies of cooperative $(p)$ and opportunistic behavior $(1-p)$ in a growing organization. We will see the group-level consequences of individual-level psychologies, decision rules, and behaviors (Henrich and Boyd, 2002; van den Bergh and Gowdy, 2009). Models of cultural learning predict the frequency of a behavioral variant in a population in the next stage of the cultural evolutionary process given its frequency in the present stage (see, as points of origin, Cavalli-Sforza and Feldman, 1981; Boyd and Richerson, 1985). Cultural transmission from one agent to another is typically emotionally or cognitively biased, i.e., people are more likely to acquire some behavioral variants than others (Richerson and Boyd, 2005; Norenzayan and Heine, 2005). For an analysis of the evolution of corporate cultures we need to understand how cognition directs cultural learning toward certain 
individuals or behavioral variants. For that purpose, we take account of intra-firm socialization processes via role models, an inherent attractiveness of the opportunistic behavior, and the influence of the frequency of a behavior within a group on the behavior of single employees.

We incorporate socialization of employees into the model by drawing on the fact that human agents are prone to adopt behaviors that are shown by role models in their social environment. A cognitive predisposition to imitate successful or prestigious individuals takes effect in cultural transmission, i.e., there is a model-based bias in social learning. Evidence from social psychology and anthropology shows that the adoption of behavioral variants is frequently conditioned by the observable attributes of individuals exhibiting the variant (e.g., Rogers, 1983; Harrington Jr., 1999; Henrich and Gil-White, 2001; Labov, 2001). An entrepreneur or business leader plays an outstanding role as a model in socialization: she provides a prestigious role model for social learning within the firm. In this role, she can motivate and coordinate firm members, foster cooperation, and hold down opportunism (Schein, 1992; Witt, 1998; 2000; Van den Steen, 2010).

Therefore, we assume that each individual employee is influenced by the entrepreneur and $n$ peers, i.e., the other employees. We assign different weights to these models to account for differing importances in socialization: $A_{E}$ denotes the entrepreneur's influence and $A_{P}$ measures the weight of an ordinary member of the group. ${ }^{2}$ Large values of $A_{E}$ imply that the employee is disproportionately likely to acquire the entrepreneur's behavioral variant. The latter's influence as a model is, however, decreasing with growing organizational size $n$. Then, the total, i.e., firm size adjusted, actual weight of the entrepreneur or business leader in socialization is given by

$$
A_{E}=\frac{\alpha_{E}}{\alpha_{E}+n \alpha_{P}}
$$

where $\alpha_{E}$ is the basic weight of the entrepreneur and $\alpha_{P}$ the basic weight of any given peer employee $\left(\alpha_{P}=\alpha_{1}=\alpha_{2}=\ldots=\alpha_{n}\right)$. Different values for $\alpha_{E}$ reflect the fact that entrepreneurs differ in their ability to exert influence on other individuals due to differences in their charismatic potential. The latter comprise traits such as social skills, authority, personal work ethic, ability to articulate a persuasive vision, etc. (e.g., Milgram, 1974; Langlois, 1998).

Accordingly, the weight of a member of an employee's the peer group is expressed by

$$
A_{P}=\frac{\alpha_{P}}{\alpha_{E}+n \alpha_{P}}
$$

Within the organization, the cumulative influence of the peer employees in socialization is growing with an increasing firm size and a dwindling role of the entrepreneur. Both weights, $A_{E}$ and $A_{P}$, are normalized by the denominator to give the weight of a model relative to the other models encountered by an individual employee.

To capture the socialization of employees in a growing organization, the model must allow us to predict the probability of agents acquiring behavior $c$ or $O$, given a particular set of models (entrepreneur, $n$ peers) that have different total weights $\left(A_{E}, A_{P}\right)$ and group size $n$ (also modifying values of $A_{E}$ and $A_{P}$ ). We assume the entrepreneur to exhibit always the cooperative behavioral variant. As is shown briefly in Appendix B and more detailed in previous work

\footnotetext{
${ }^{2}$ Accordingly, $n A_{p}$ reflects the weight of an employee's fellow employees, whereby $A_{E}+n A_{p}=1$.
} 
(Cordes et al., 2008; 2011), given the average pairing probability of role models and their changing weights in socialization, we yield a $A_{E}+p n A_{P}$ probability of transmitting behavior $c$ to each member of the firm. Thus, the partial recursion for the socialization phase with the frequency of $c$ after transmission, $p^{\prime}$, given that it was $p$ before, is expressed by

$$
p^{\prime}=A_{E}+p n A_{P}
$$

Another social learning bias important to understand an individual's behavior in groups is the conformity bias: employees are more likely to pick the behavioral variant that is modeled by the majority of the organization's members, whereas they discriminate against behaviors that are rare in the group. Anthropological and psychological evidence indicates the existence of such a heuristic in social learning (Aronson et al., 2002; Kameda and Diasuke, 2002; Cialdini and Goldstein, 2004; Henrich, 2004). As shown below, peer employees' behaviors are crucial in both maintaining a high level of cooperation and moving a corporate culture away from that regime toward the prevalence of opportunistic behavior. Finally, we incorporate a direct bias in cultural learning. An employee may recognize, by observing colleagues behaving opportunistically, the personal extra benefits accruing from this kind of behavior. As a consequence, she may lower effort for the firm's goals implying an increased relative importance of her selfish interests.

Equation (7) formalizes the effects of conformist and direct bias within a group of interacting members (see Henrich, 2001). As is shown in Appendix C, the frequency of $c$ after these learning steps, $p^{\prime \prime}$, given that it was $p^{\prime}$ before, is expressed by

$$
p^{\prime \prime}=p^{\prime}+p^{\prime}\left(1-p^{\prime}\right)\left\{\eta\left(2 p^{\prime}-1\right)-(1-\eta) \mu_{c o}\right\} \text {. }
$$

The term $\left(2 p^{\prime}-1\right)$ measures the conformist bias and takes on values between -1 and 1 . When the frequency of cooperative behavior among employees is less than one half, the conformity bias is negative promoting opportunism as the majority behavior in the group. When $p^{\prime}>0.5$, it favors the cooperative behavioral variant. The final term in (7) models the direct bias, $\mu_{c o}\left(0 \leq \mu_{c o} \leq 1\right)$, continuously increasing the share of the opportunistic behavioral variant, $o$, in the group (Boyd and Richerson, 1980; Richerson and Boyd, 2005). We suppose that each $c$ employee has a $\mu_{c o}$ chance of switching to this behavior. Parameter $\eta$, which varies between 0 and 1 , gives the strength of conformity relative to the direct bias in human cognition, i.e., it scales the cognitive weight given to the frequency of a behavior in a group (Henrich, 2001).

The complete recursion for $p$, depicting the change in intraorganizational cooperation as an indicator of a firm's culture, over one socialization phase and one conformist learning step including a direct bias favoring opportunistic behavior, is obtained by substituting (6) into (7). We then yield a two-dimensional system of coupled recursions, one for the development of $p(8)$ and another one for the changing size of a firm (9) $\left(p^{\prime \prime}-p=\Delta p, n^{\prime}-n=\Delta n\right)$ :

$$
\begin{aligned}
& \Delta p=\left(A_{E}+p n A_{P}\right)+\left(A_{E}+p n A_{P}\right)\left(1-\left(A_{E}+p n A_{P}\right)\right)\left\{\eta\left(2\left(A_{E}+p n A_{P}\right)-1\right)-(1-\eta) \mu_{c o}\right\}-p \\
& \Delta n=n\left(p\left(1+r_{c}\right)+(1-p)\left(1+r_{o}(n)\right)-1\right)\left(1-\frac{N}{K}\right)-n(S) .
\end{aligned}
$$


While this dynamic system can be solved analytically, the resulting terms are too complex to be interpreted in a straight forward manner. ${ }^{3}$ We can, however, visualize its dynamic properties to discuss its implications by choosing parameter values and iterating the system for many cultural transmission and firm growth steps.

This is done in Figure 1 that depicts the evolution of the frequencies of cooperative behavior as indicators of organizations' cultures in a set of three representative firms (F1-3) when there are no spinoffs $(n(S)=0)$ and no initial growth constraints due to intra-industry competition $(N / K$ is close to zero in the beginning; $K$ is constant). All firms start from high levels of cooperation $\left(p_{\text {start }}=0.6\right)$. For different values of $\alpha_{E}$, the entrepreneur's charismatic potential, we observe different critical cognitive firm sizes. When an organization reaches this size, the continuous introduction of opportunistic behavior by the direct learning bias, $\mu_{c o}$, and a dwindling influence of the entrepreneur as a model allow for the rapid spreading of self-interested behaviors. While having stabilized the preceding cooperative regime, the conformity bias now spurs the dissemination of the more frequent behavior $o$. The level of $p$, therefore, drops rapidly after the firm has reached this critical cognitive size: employees who are willing to contribute to the benefit of the organization and who are motivated by a cooperative culture, rather suddenly change behavior when the firm reaches the critical group size (Schelling, 1972; Grofman, 1974; Gladwell, 2000; Card et al., 2008). Figure 1 also shows that $p$ increases again as firm size shrinks (F1 and F2) due to the fact that the entrepreneur's influence rises again in smaller groups. It does not, however, reach the pre-crisis levels of intraorganizational cooperation.

(1)

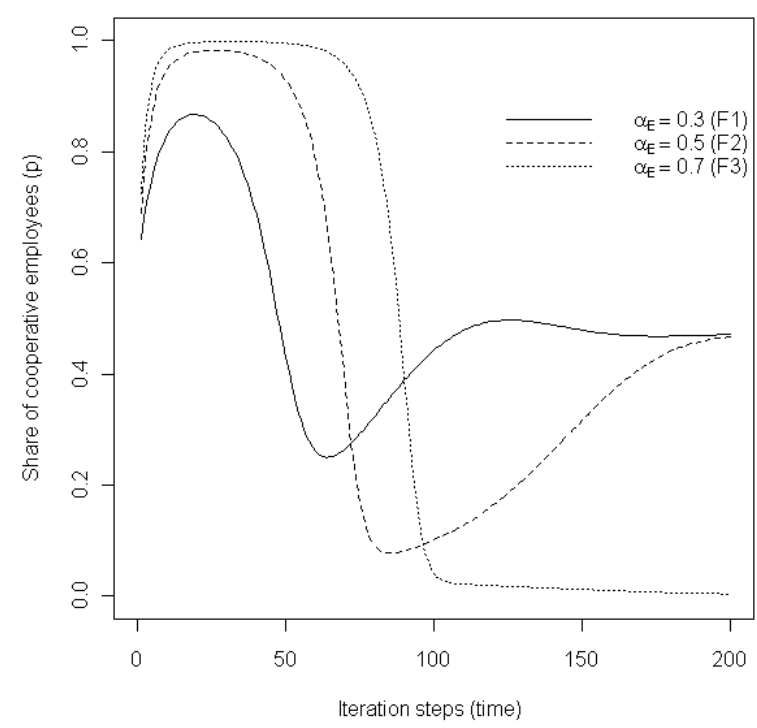

(2)

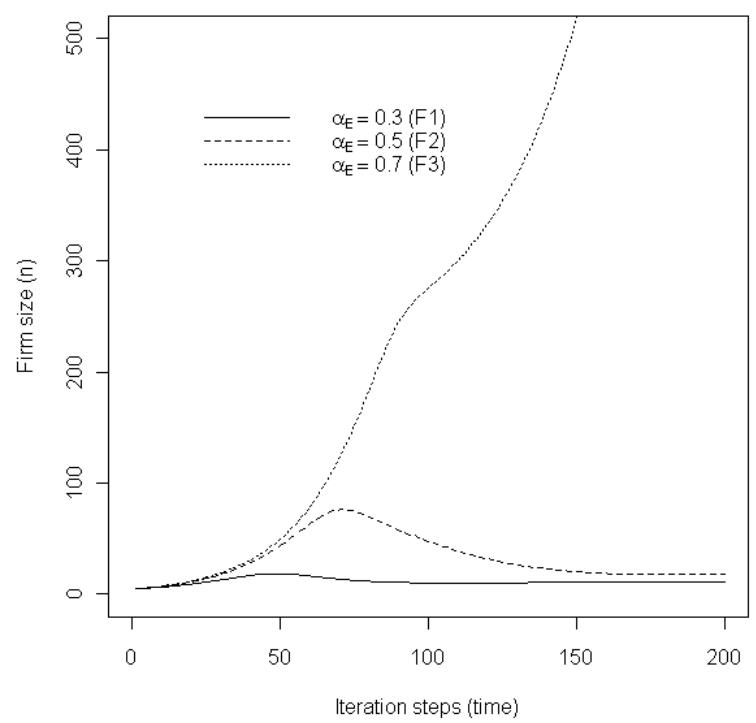

Figures 1 and 2. The evolution of three representative corporations' cultures (1) and their corresponding firm growth paths (2)

$\left(\eta=0.1, \mu_{c o}=0.3, \alpha_{P}=0.2, r_{c}=0.05, K=3000, n_{\text {crit_tech }}=200, p_{\text {start }}=0.6, n_{\text {start }}=5\right)$

\footnotetext{
${ }^{3}$ The corresponding author will provide exact analytical solutions upon request.
} 
Figure 2 illustrates the growth processes for the three representative firms given the setting described above. Initially, in an innovative business environment where high levels of cooperation yield competitive advantages, firms based on a cooperative culture can experience periods of rapid growth. We see, however, that firms have different growth potentials at this stage of their development: the higher the entrepreneur's charismatic potential, $\alpha_{E}$, the longer the firm's cooperation-driven growth process lasts and the higher is its number of employees before it reaches the critical cognitive size. The observed range of critical cognitive firm sizes depends, among other things, on the distribution of charismatic potentials in the pool of entrepreneurs. We argue that organizations inevitably reach this critical threshold during their growth process. ${ }^{4}$ One firm in our sample, F3, the one with the most influential entrepreneur $\left(\alpha_{E}=0.7\right)$, reaches the critical technological firm size before moving beyond the critical cognitive size that would result in rapid firm shrinkage. Its growth path exhibits a period of slower growth sandwiched between phases of rapid organizational development, i.e., also in this case the firm goes through a growth crisis. Overall, this organization experiences continuous growth while the other two firms face decline in the long-run. ${ }^{5}$ It can be seen from Figure 1 that the successfully growing firm F3 is characterized by a culture that can handle a high share of opportunistic agents (low $p$ ). A formalized regime of monitoring routine performances in a later, stable business environment prevents costly opportunistic behavior and enables the realization of economies of scale.

\subsection{The triggering of spinoffs}

We differentiate three stages during the development of a corporation's culture as to the firm organization's probability of generating spinoffs, measured by $P_{S}(p, N)$ : (1) If the level of cooperation among employees, $p$, lies between one and an upper threshold, $p_{\text {high }}$, no potential founder leaves the firm for they still enjoy a highly cooperative organizational environment. (2) When, however, the level of cooperation drops further, employees worried about this decline in corporate culture start to look for alternatives including starting an own enterprise. (3) This effect holds until $p$ falls beneath a lower threshold, $p_{\text {low }}$, where the firm's culture stops providing a powerful "training ground" for potential entrepreneurs. These three cases are defined by the following expression in which we assume a simple linear dependence of $P_{S}$ on $p$ and $N$ :

$$
P_{S}(p, N)=\left\{\begin{array}{cc}
(1-p)\left(1-\frac{N}{K}\right) & \forall p \in\left[p_{\text {low }}, . ., p, \ldots, p_{\text {high }}\right] \\
0 & \text { else }
\end{array}\right.
$$

Spinoff probability also depends on the number of employees active in the industry and thus the intensity of competition: given a certain market potential, $K$, spinoff probability decreases with an increasing $N$. Schumpeter (1939) already emphasized the role of unexploited commercial opportunities in providing stimuli for employees to create their own firms.

\footnotetext{
${ }^{4}$ The exact critical cognitive size at which cooperation collapses depends on several aspects external to our model: e.g., the maturity of the group, the personalities of its members, the details of a firm's norms, or general cultural influences. The deleterious effects on collective outcomes of increasing group size may partly be overridden when collective identity is high (Brewer and Kramer, 1986; Wagner III, 1995; Akerlof and Kranton, 2005). In any case, we argue that it should be possible to determine a certain range of group sizes wherein these effects become eminent. ${ }^{5}$ Organizations of an intermediate size are especially vulnerable to failure, an observation for which there is empirical and theoretical evidence (e.g., Hannan and Freeman, 1977; Boone et al., 2004).
} 


\section{The triggering of spinoffs, the provision of ideal "training grounds", and an industry's genealogy}

Analyzing the properties of the two coupled recursions (Equations (8) and (9)) describing a firm's evolving corporate culture and the development of organizational size in different business environments yields interesting implications regarding the triggering of spinoffs, their distinct pre-entry capabilities, and an industry's evolution when combined with our expression for the generation of spinoffs (Equation (10)).

There are several triggering events of spinoffs discussed in the literature (e.g., Klepper and Thompson, 2010). Buenstorf (2009), for instance, distinguishes necessity spinoffs from opportunity spinoffs. While the former are triggered by deteriorating job conditions within the parent firm that may culminate in involuntary exit, the latter are caused by business opportunities perceived by an employee of an incumbent firm. While both factors are prominent in our approach, we first focus on necessity spinoffs. Employees may observe the drop in the level of cooperation within the parent firm and the corresponding rise in opportunistic behavior. This entails a new corporate culture with less discretion and autonomy on the part of the employees and more monitoring of their activities to keep in check rising opportunism. Some agents will consider this kind of organizational development as an indicator of a growth-induced crisis and leave the firm to go for a necessity spinoff. ${ }^{6}$ We therefore suggest this kind of a parent firm's crisis as a triggering event of spinoffs:

Proposition 1. A parent firm's evolving corporate culture is a triggering mechanism of spinoffs: with increasing firm size, a cooperative regime is becoming more and more

difficult to sustain. The final drop in the level of cooperation is motivating entrepreneurially minded agents to leave the organization to found a spinoff.

In our model, organizational aspects rooted in human cognition condition the creation of new firms: systematically appearing growth crises in firm development trigger spinoffs. At the point of their cognitive critical size, firms tend to become socially unstable and prone to social disaggregation. Figure 3 shows three firms' (F1-3) changing shares of cooperative agents as measured by their respective values of $p$. The three organizations in the sample are lead by entrepreneurs that differ in their charismatic potentials. We again see the occurrence of distinct growth crises when the organizations reach critical cognitive sizes. In each iteration step during these growth crises, when $p$ lies between $p_{\text {low }} \leq p \leq p_{\text {high }}$, firms generate a spinoff with a certain probability, as has been defined by Equation (10). ${ }^{7}$ The case depicted here is a typical one coming out of the probabilistic part included in this expression. While firm F1 does not have a spinoff in this scenario, firms F2 and F3 are more prolific in this regard and give rise to two spinoffs each (S1-2 and S3-4). ${ }^{8}$ Due to the fact that F3 reaches its critical cognitive size later than F2, the former's spinoffs S3 and S4 enter the market after the spinoffs of F2 (S1-2) that therefore may enjoy relative first mover advantages. All the spinoffs in this sample rapidly reach high levels of intraorganizational cooperation due to small initial group sizes and relatively high

\footnotetext{
${ }^{6}$ Garvin (1983) argues that employees leave to start their own firms after becoming frustrated with their employers. The drop in cooperativeness resulting from firm growth provides such a source for frustration.

${ }^{7}$ In the case shown here, we assumed this range to lie between $0.5 \leq \mathrm{p} \leq 0.8$.

${ }^{8} \mathrm{We}$ assume teams of five employees to leave the parent organizations. Furthermore, we allow a spinoff to happen if the parent firm's size exceeds this spinoff size fivefold.
} 
values of $\alpha_{E}$ that are passed on to the new firms through entrepreneurial imprinting and that also influence their subsequent performance (as discussed below). ${ }^{9}$

(3)

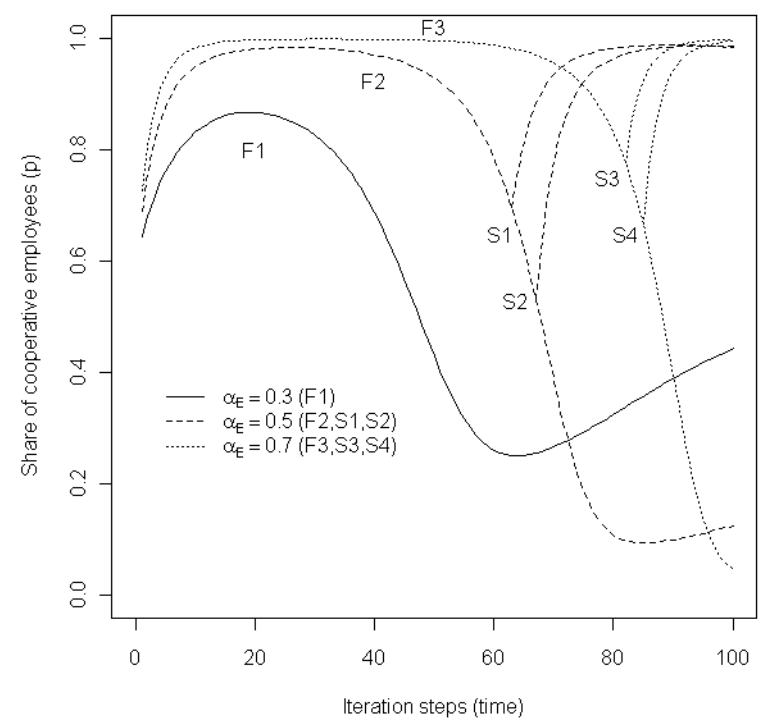

(4)

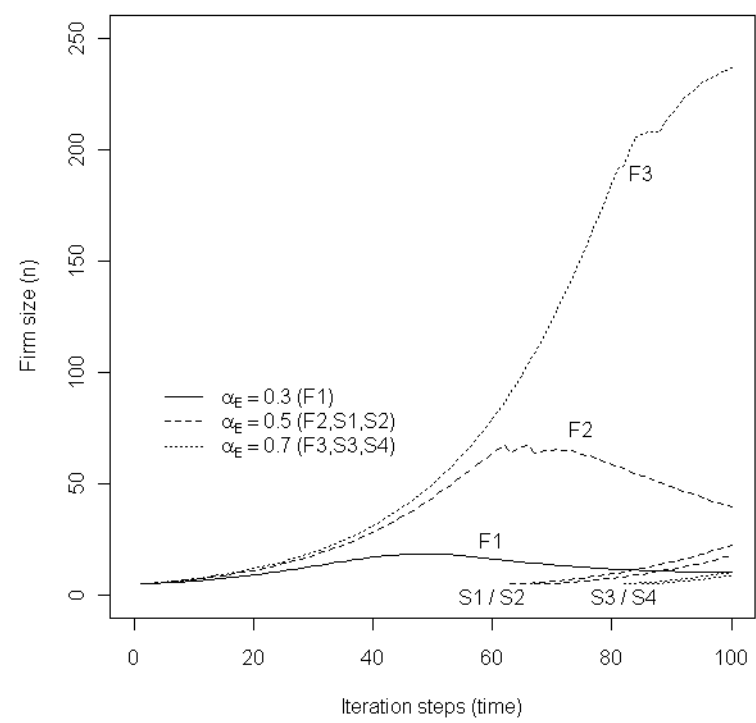

Figures 3 and 4. The spawning of spinoffs as a result of growth crises (3) and the organizations' growth paths (4)

$$
\left(\eta=0.1, \mu_{c o}=0.3, \alpha_{P}=0.2, r_{c}=0.05, K=3000, n_{\text {crit_tech }}=200, p_{\text {start }}=0.6, n(S)=5\right)
$$

Figure 4 illustrates the growth paths of the parent firms and their spinoffs. Firm F3 attains the critical technological size before moving beyond the critical cognitive size and exploits the advantages of a later, stable business environment. This happens although some employees leave the organization to found spinoffs, which leads to a - in this case transient - fall in a firm's number of employees, an effect reflected by the term $n(S)$ in Equation (9). Depending on the exact specification of $n(S)$ and the evolution of the business environment, we can imagine scenarios in which firms do not reach the critical technological size because of strong spinoff activity. However, the parent firm's performance in a dynamic market might also improve if employees leave for own businesses: the intraorganizational level of cooperation increases in the now smaller group given a certain charismatic potential of the entrepreneur, $\alpha_{E}$. Therefore, the exit of competing role models in employee socialization may restore the entrepreneur's influence. ${ }^{10}$ Moreover, also leadership changes can be a trigger for spinoffs mediated by changes in a corporation's culture: a new CEO may have a lower influence in socialization than her predecessor causing a decline in intraorganizational cooperation thus motivating employees to leave to start their own firms. Indeed, empirical evidence shows that spinoffs are more likely in firms whose CEO has recently changed (Eriksson and Kuhn, 2006).

\footnotetext{
${ }^{9}$ In a dynamic business environment, these spinoffs enjoy competitive advantages from their high levels of cooperation. However, in a stable environment, this relative advantage diminishes because opportunistic agents start to contribute to firm profits and an increasing share of the business opportunity is exploited by incumbent firms.

${ }^{10}$ McKendrick et al. (2009) provide empirical evidence that spinoffs can have a positive impact on parent firms. The effect mentioned here may be one of those mechanisms fostering the parent's development.
} 
A decline in a group's members willingness to cooperate with increasing group size is a common phenomena in social psychology and experimental economics (e.g., Olson, 1994; Spoor and Kelly, 2004). As a group grows larger, many problems appear: there is more misbehavior, free riding, members of larger groups tend to be less satisfied with their membership, are absent more often, contribute less often to group activities, and are less likely to cooperate with one another (Markham et al., 1982; Albanese and van Fleet, 1985; Brewer and Kramer, 1986; Kerr, 1989; Levine and Moreland, 1990; 1998; Mukhopadhaya, 2003; Forsyth, 2006, ch. 9). A metaanalysis of 31 field studies of the size-performance relationship of firm organizations by Gooding and Wagner (1985) indicates that there is a consistent negative subunit size-performance correlation (also Wagner III, 1995). Coordination problems and motivation losses in larger, more anonymous groups often prevent reaping the productive potential that larger groups offer. In contrast, inclusion within a small, intensely - via face-to-face contacts - interacting group reduces social distance among its members weakening the sharp distinction between their own and others' welfare and goals.

These aspects of group life have deep roots in humans' evolutionary past. Anthropology provides some concrete numbers for the observation of a critical group size. Marlowe (2005) reviews the group sizes among hunter-gatherers whose way of life most closely resembles those of our Pleistocene ancestors. Base on a sample size of 294 cases, local residential groups (bands) averaged 48 (median 30) people. These local groups are nested within ethno-linguistic groups (tribes), whose sizes average $1750(n=396) .{ }^{11}$ The author found no indication of local group sizes depending on resources. Instead, the upper limit on their size is determined by the frequency of bickering, reflecting an increase in free riding. Studies from economics on village scale commons management suggest that small, band-based systems can be maintained by informal agreements, but that larger systems require formal rules as well as monitoring and sanctions (Ostrom, 2009). Therefore, the band-sized group may represent the limits of cooperation organized by purely informal means, for example, by leadership of a charismatic entrepreneur, and would thus define the approximate range of our critical cognitive firm sizes. Larger organizations probably require explicit norms and institutions as well as subdivisions to function when they get above a size of 50 or so, if the analogy with bands and tribes is correct. Thus, one organizational strategy to avoid cooperative collapse is the implementation of an intraorganizational subdivision of entrepreneurship to keep parts below the critical cognitive size, while allowing for growth of the organization as a whole. Sub-leaders assigned to these subdivisions would then be capable of maintaining cooperative cultures in their groups (Witt, 2007; Cordes et al., 2010).

As to the occurrence of opportunity spinoffs, we argue that a cooperative corporate culture endows employees with capabilities that enable them to better identify profitable business opportunities, i.e., it also makes opportunity spinoffs more likely. ${ }^{12}$ This relates to the important stylized empirical fact that market entry by spinoffs is superior to other forms of entry (e.g., Eriksson and Kuhn, 2006; Dahl and Reichstein, 2007). We suggest the following proposition:

Proposition 2. Firms with cooperative cultures active in dynamic business environments spawn more spinoffs because they are ideal "training grounds" for potential founders.

Due to the higher degree of autonomy, responsibility, and discretion left to employees in a cooperative culture, these agents are more likely to attain crucial skills for running an own firm as

\footnotetext{
${ }^{11}$ There is a human disposition to identify with larger, symbolically marked groups and norms and institutions characterizing these groups. Such groups still depend, however, upon the moral dispositions that help stabilize cooperation in local band-scaled groups as their constituents (Richerson and Boyd, 2005).

${ }^{12}$ A firm's deteriorating culture can then be the final impetus for going for the perceived business opportunity.
} 
well as to perceive new business opportunities, for example, in niches and submarkets. The success of organizations with a cooperative regime in dynamic business environments results in the accumulation of more valuable knowledge and enables more encompassing learning processes on the part of its employees. These organizations provide an environment in which an "entrepreneurial spirit" is much more common among the organization's members (e.g., Christensen, 1993; Franco and Filson, 2006). Higgins (2005) shows how Baxter International, a U.S. manufacturer of medical supplies, enabled its executives to acquire an "entrepreneurial imprint" during their socialization phase within the firm. Having been trained on challenging and largely autonomous jobs in a highly cooperative environment, these employees played an outstanding role as spinoff entrepreneurs in the emerging biotechnology industry. Moreover, Ellis et al. (2008) found that Israeli high-tech firms active in dynamic business environments have higher spinoff rates hinting at their effectiveness as "training grounds" for spinoff founders.

A cooperative regime enhances the extent to which entrepreneurial skills can be acquired within a firm especially in dynamic business environments. In contrast, a firm culture based on monitoring does not serve as an equally effective incubator for entrepreneurially minded agents for a relatively greater share of intraorganizational learning is restricted to routine tasks and employees do not enjoy a great degree of autonomy. Given our finding that small organizations are more likely to sustain a cooperative culture, we expect small firms or subdivided enterprises to be better incubators for potential spinoff founders. Empirical evidence indicates that employees of larger firms are less likely than those of smaller organizations to found spinoffs (e.g., Elfenbein et al., 2010). Eriksson and Kuhn (2006) and Sørensen (2007) found that larger ventures adapted to mature business environments spawn less spinoffs than smaller firms due to a negative effect of bureaucratic structures on innovation and managerial flexibility (see also Arrow, 1974, p. 49; Teece et al., 1997). What is more, several empirical studies show that the performance of spinoffs is better for those founded by employees of smaller firms (e.g., Sørensen, 2007; Elfenbein et al., 2010). Garvin (1983) presents evidence from a number of industries about spinoffs being concentrated in infant industries dominated by small corporations. Hence, initially high spinoff rates of small firms may reflect a rich, dynamic, and accessible knowledge base for employees to draw on (Klepper and Sleeper, 2005). Therefore, we argue that spinoffs are more prevalent in industries characterized by a dynamic business environment that favors cooperative cultures in small firms or organizational sub-units. With a changing corporate culture in more mature business environments, spinoff rates fall off. ${ }^{13}$

There is strong empirical evidence suggesting that, on average, firms founded by exemployees of industry incumbents are particular successful entrants (e.g., Klepper, 2002; Buenstorf and Klepper, 2009). Pre-entry learned skills are crucial for spinoff performance (e.g., Garvin, 1983; Franco and Filson, 2006). Moreover, among an industry's spinoffs, those founded by employees of better performing firms tend to outperform other spinoffs (Klepper and Sleeper, 2005; Klepper, 2009). Successful parent firms endow their spinoffs with valuable capabilities and new firms are fundamentally shaped by the experiences of their founders (Van den Steen, 2010). This leads to the following proposition:

Proposition 3. Ceteris paribus, the greater the entrepreneur's influence in employee socialization, the higher and enduring is the level of intraorganizational cooperation and the more successful the firm is in a dynamic business environment. As a result, employees enjoy a stronger "entrepreneurial imprinting" and a longer period of learning in such a

\footnotetext{
${ }^{13}$ Firms more advanced along the industry life cycle have lower spinoff rates also for other reasons: e.g., valuable knowledge becomes more embodied in physical capital making it less accessible to employees (Garvin, 1983; Klepper and Sleeper, 2005).
} 
stimulating environment. Both effects make spinoffs originating from these parent organizations more successful vis-à-vis other market entrants. Spinoffs attain specific capabilities from their parent firms that shape their nature at their founding time.

We capture the "entrepreneurial imprinting process" (Higgins, 2005) by assuming that the parent firm's entrepreneur passes on her $\alpha_{E}$ to the spinoff founders originating from her organization. This occurs directly via socialization and indirectly via intraorganizational learning: a high level of cooperation, which crucially depends on the entrepreneur's $\alpha_{E}$, provides an environment in which valuable experiences are made that increase founders' later influence as role models within their own organizations. As a consequence of these differential endowments by the parent firms, spinoffs differ according to their origins.

(5)

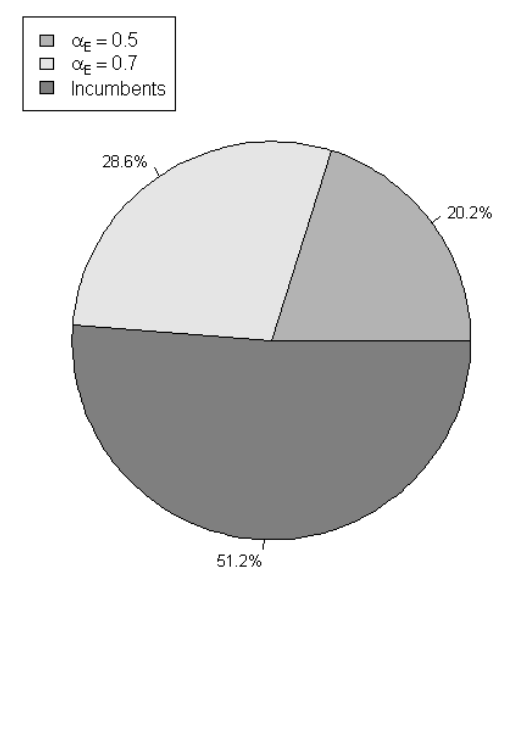

(6)

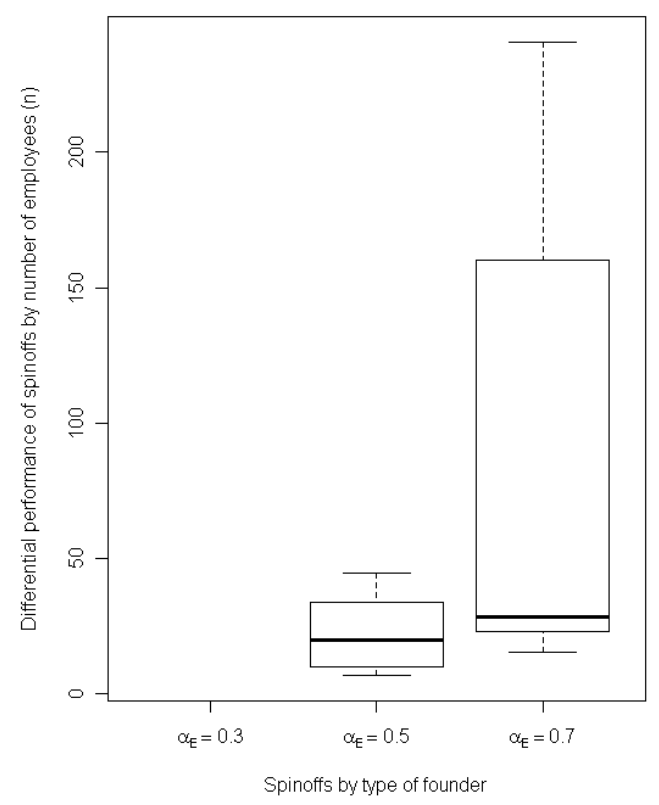

Figures 5 and 6. The distribution of employees over different types of spinoffs and incumbents (5) and spinoffs' differential performance (6)

Starting from our initial set of three spinoff-generating parent firms, 1000 simulation runs over 300 time steps generated, on average, zero spinoffs of type $\alpha_{E}=0.3,14$ spinoffs of type $\alpha_{E}=0.5$, and 5 spinoffs of type $\alpha_{E}=0.7$. Figure 5 gives the resulting employment shares of spinoffs of different kind and incumbents. Spinoff founders of type $\alpha_{E}=0.7$ account for a greater share in total employment than those of type $\alpha_{E}=0.5$. The "endowment effect" of spinoffs becomes obvious if we measure firm performance by the number of employees working with each type of spinoff as illustrated in Figure 6: given this indicator of firm success, spinoffs with higher values of $\alpha_{E}$, i.e., those with more influential entrepreneurs in intraorganizational learning, on average employ more agents. These spinoff founders have enjoyed the strongest "entrepreneurial imprinting" while being with their parent organizations. Figure 6 shows that while the median of spinoff performance is only slightly higher in the case of spinoffs of type $\alpha_{E}=0.7$ (as indicated by the bold horizontal bars), the variance in the number of employees is 
much larger. Consequently, the chance to observe highly successful spinoffs is higher for organizations founded by more charismatic entrepreneurs.

Successful regions or industries are driven by entrepreneurship, i.e., a high rate of new firm formation is vitally important to their success (Garvin, 1983). In Figure 7, we see an exemplary lineage of an industry's spinoffs derived from the model. The genealogy of, for instance, Silicon Valley start-up firms shows the importance of such a "fissioning" process based on spinoff activity (see Moore and Davis, 2004). In this region, many spinoffs can be traced back to a few firms - Fairchild Semiconductor alone was the origin of 124 spinoffs. Hence, the proliferation and success of spinoffs originating from only a couple of parent firms drove the growth of Silicon Valley. A similar role of spinoffs as the driving-force of industry evolution is shown by Klepper (2002) for the automobile industry and by Kenney and von Burg (1999) for the LAN industry.


Figure 7. An exemplary genealogy of spinoffs in an industry generated by the model

Proposition 4. The ongoing generation of spinoffs via firm growth crises is one driving force behind the emergence of regional genealogies of organizations that can be traced back to few pioneering ventures.

Given that pre-entry experiences of founders play a crucial role and that existing firms with cooperative corporate cultures are an ideal training ground for new entrants, an industry or region endowed with many firms of this kind can profit from the availability of a great number of entrepreneurially skilled agents as potential spinoff founders. The exodus of this personnel from established firms can then initiate a self-reinforcing processes of firm creation, exploitation of business opportunities, and regional or industrial development (e.g., Kenney and von Burg, 1999). Although many regions have, for example, universities that provide well-educated, creative agents that may become entrepreneurs, the additional existence of a number of firms that offer the opportunity to gain on-the-job entrepreneurial experiences is essential to trigger such a development. The structure and characteristics of organizational populations affect the supply of nascent entrepreneurs (e.g., Sørensen, 2007). 
Figure 8 illustrates the effects of a constant market potential, as measured by parameter $K$, on spinoff formation. While we observe the emergence of spinoffs in the beginning of industry evolution, these market entrants disappear as the market potential is exploited by incumbent firms. As long as $K$ is large relative to the aggregate number of employees in the industry, $N$, the probability that changes in a corporation's culture can trigger spinoffs is large, as has been specified by Equation 10. The existence of unexploited business opportunities is therefore a prerequisite for dynamic spinoff processes to happen.

Proposition 5. Ingredients for a successful region are an unexploited business opportunity $(K)$, a (low) number of young, rather small firms whose corporate cultures are based on cooperation (high $p$ ) that provide ideal "training grounds" for potential entrepreneurs, and a (initially small) pool of skilled entrepreneurs endowed with a high charismatic potential $\left(\alpha_{E}\right)$ that facilitates entrepreneurial imprinting of their employees and potential spinoff founders.

An important difference between Silicon Valley and Route 128 that has determined their differential economic performance was to be found in the different market potentials of their industries, i.e., the semiconductor versus the minicomputer industry (Kenney and von Burg, 1999). Figure 9 illustrates the case of a growing market potential that allows for the appearance of spinoffs and continuous firm growth also later in an industry's life cycle. The extension of an industry's business opportunity can be endogenous: several studies show that spinoffs can enhance an industry's overall market potential benefiting all incumbent firms (e.g., Higgins (2005) for the biotechnology industry and Klepper and Sleeper (2005) for the laser industry).

(8)

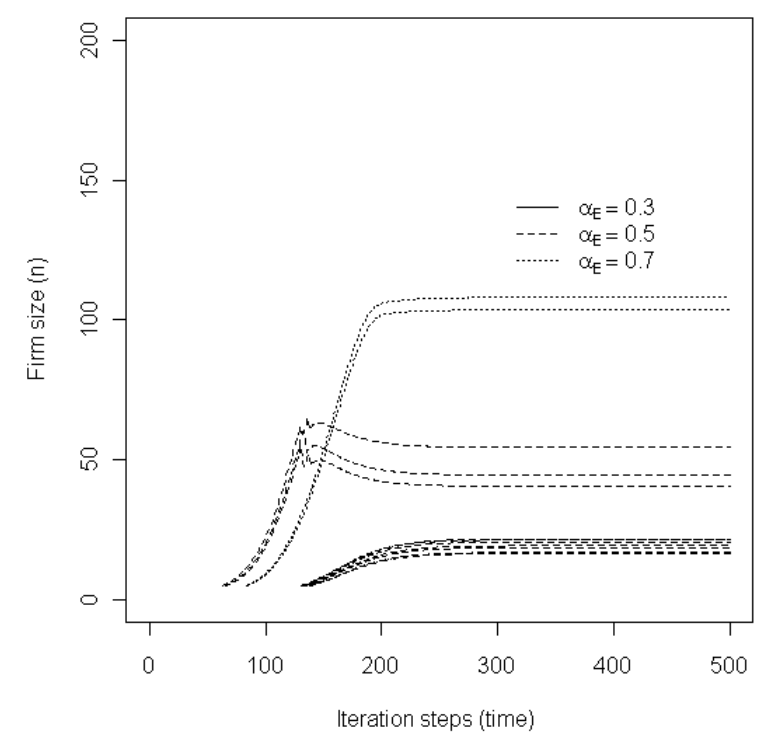

(9)

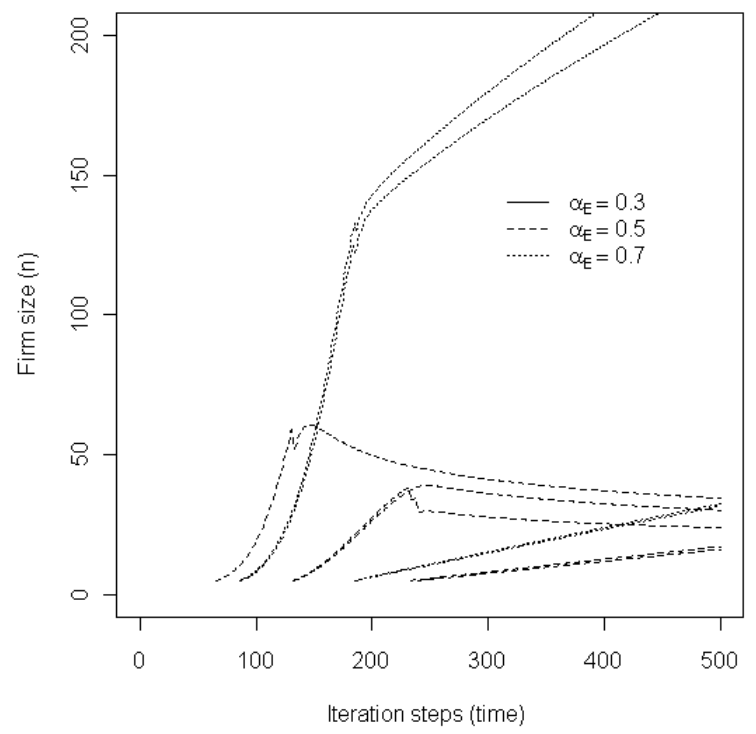

Figures 8 and 9. Spinoff generation with constant capacity $K(8)$ and growing capacity (9), where we add 5 units of capacity for each spinoff entering the industry 


\section{Conclusions}

We suggested a model of organizational development to explain some facets of the regular occurrence of spinoffs in industry evolution. We brought forward the core idea that changes in a venture's corporate culture can be an impetus for spinoff formation. During their growth process, organizations systematically reach a critical cognitive size beyond which the initially high level of cooperation deteriorates. These firm growth crises can motivate entrepreneurially minded employees to leave the organization to found a spinoff. Moreover, a parent firm's culture also influences the further development of these new organizations. Cooperative corporate cultures, in contrast to cultures based on monitoring, provide ideal "training grounds" for potential spinoff founders and endow these with crucial capabilities and pre-entry experiences. We have shown that our model can explain various stylized facts that have been accumulating in empirical works regarding the generation and performance of spinoffs (see Klepper, 2009). Finally, we related our findings on the level of the firm to an industry's evolution. We demonstrated how ongoing spinoff processes can generate genealogies of firm organizations. Moreover, we discussed the ingredients necessary for successful regional or industrial development, especially the availability of a pool of well-endowed potential firm founders in combination with entrepreneurial opportunity. As spinoffs and their role in industrial evolution gain increasing attention in research, new theories are necessary to guide the discussion and further empirical work.

Our focus on evolving corporate cultures as an impetus for spinoffs resonates well with a number of other approaches that emphasize the role of firm cultures in organizational and industrial development (Schein, 1992; Hermalin, 2001; Van den Steen, 2010; Kosfeld and von Siemens, 2011). Of course, we do not deny the importance of factors such as incentive and ownership structure, legal settings, employment contracts, or financial circumstances in the context of a business's development. There are, however, additional - behavioral - aspects that are worthwhile a closer scrutiny to understand organizational development: intra-firm learning and socialization processes, systematically appearing growth crises due to increasing group size, and employees that may profit form the former while taking the latter as an impetus to leave the organization to start their own firms, thereby influencing an industry's evolutionary path.

\section{Appendix A}

- The general form of logistic models is the following:

$$
n^{\prime}=n+x n\left(1-\frac{\sum_{i} n_{i}}{K}\right),
$$

where the growth rate of $n$ is denoted by $x$. We can derive this growth rate form $n^{\prime}$ given by Equation (1) in the text:

$$
\begin{aligned}
& x=\frac{n^{\prime}-n}{n}=\frac{1}{n}\left(p n\left(1+r_{c}\right)+n(1-p)\left(1+r_{o}(n)\right)-n\right), \\
& =p\left(1+r_{c}\right)+(1-p)\left(1+r_{o}(n)\right)-1 .
\end{aligned}
$$

which gives the growth rate used in Equation (3). 


\section{Appendix B}

- In order to account for the effects of new personnel joining the firm and the necessary "renewal" of the socialization of existing employees, who are then considered as if they were personnel just joining the firm, we suppose that in each time step a cohort of $n$ employees "retires" and is replaced by $n$ new employees who are socialized by all $n$ old employees, plus the entrepreneur. In addition, we assume that all new employees show neutral behavior when they join the firm. Moreover, these new firm members encounter other employees at random. With the help of the cultural transmission table below (Table B1), we specify the probability that a particular set of role models with different weights makes an individual acquire the behavioral variant $c$ or $o$, given a changing group size.

Table B1 The probability of agents acquiring behavior $c$ or $O$ given a particular set of models (Entrepreneur/Leader, Peers) that have different total weights $\left(A_{E}, A_{P}\right)$.

\begin{tabular}{|c|c|c|c|}
\hline \multicolumn{2}{|c|}{ Behavioral Variant of } & \multicolumn{2}{|c|}{$\begin{array}{c}\text { Probability That an Agent of the New Cohort Acquires } \\
\text { Behavioral Variant }\end{array}$} \\
\hline Entrepreneur/Leader & $n$ Peers & C & $O$ \\
\hline$c$ & $C \ldots C$ & $A_{E}+n A_{P}$ & 0 \\
\hline$C$ & C...C, $O$ & $A_{E}+(n-1) A_{P}$ & $A_{P}$ \\
\hline c & C...C, $O, O$ & $A_{E}+(n-2) A_{P}$ & $2 A_{P}$ \\
\hline$\vdots$ & $\vdots$ & $\vdots$ & $\vdots$ \\
\hline C & $O \ldots O$ & $A_{E}$ & $n A_{P}$ \\
\hline
\end{tabular}

The variable $p$ measures the frequency of the $c$ type in an infinite meta population of firms of size $n$. That is, for illustrative simplicity we are here modeling only the deterministic effect of evolutionary processes. In any given firm, stochastic effects will be important. However, in an infinite population of firms with particular characteristics, $p$ will perfectly describe the average frequency of the cooperative behavior and $(1-p)$ the opportunistic behavior. Therefore, the average pairing probability of role models in the transmission table will have $A_{E}+p n A_{P}$ probability of transmitting $c$ to each new member of a cohort and probability $(1-p) n A_{p}$ of transmitting the behavioral variant $o$. Thus, in an infinite population of firms of size $n$, the partial recursion for the socialization phase with the frequency of $c$ after transmission, $p^{\prime}$, given that is was $p$ before transmission, is expressed by Equation (6) in the text.

\section{Appendix C}

- We assume employees to choose an individual at random from the total number of a firm's employees. Due to the direct bias $\mu_{c o}$ alone, which captures the attractiveness of opportunistic behavior, agents are probabilistically more likely to adopt behavior $o\left(0 \leq \mu_{c o} \leq 1\right)$ when they encounter it or to stick to it if they already behave opportunistically and meet a cooperative colleague. In addition, the conformist component, $\left(2 p^{\prime}-1\right)$, which depends on the frequency of 
behavior $c$ in the firm, modifies the adoption probabilities as described in the text. Then, the probabilities of switching are given by Table $\mathrm{C} 1$.

Table C1 The probability of employees acquiring $c$ or $O$ given the behavior encountered.

\begin{tabular}{|c|c|c|c|}
\hline \multicolumn{2}{|c|}{ Behavioral Variant of } & \multicolumn{2}{|c|}{$\begin{array}{c}\text { Probability That an Agent Acquires } \\
\text { Behavioral Variant }\end{array}$} \\
\hline Self & Other & C & $O$ \\
\hline$C$ & $C$ & 1 & 0 \\
\hline C & $O$ & $\frac{1}{2}\left\{1+\left[\eta\left(2 p^{\prime}-1\right)-(1-\eta) \mu_{c o}\right]\right\}$ & $\frac{1}{2}\left\{1-\left[\eta\left(2 p^{\prime}-1\right)-(1-\eta) \mu_{c o}\right]\right\}$ \\
\hline$o$ & $C$ & $\frac{1}{2}\left\{1+\left[\eta\left(2 p^{\prime}-1\right)-(1-\eta) \mu_{c o}\right]\right\}$ & $\frac{1}{2}\left\{1-\left[\eta\left(2 p^{\prime}-1\right)-(1-\eta) \mu_{c o}\right]\right\}$ \\
\hline$o$ & $o$ & 0 & 1 \\
\hline
\end{tabular}

Using the probabilities of each possible pairing of "Self" and "Other", we can calculate the frequency of behavior $c$ after this kind of transmission process by multiplying the former by the different probabilities of switching to behavior $c$. We get the following recursion:

$$
p^{\prime \prime}=p^{\prime 2}[1]+2 p^{\prime}\left(1-p^{\prime}\right)\left[\frac{1}{2}\left\{1+\left(\eta\left(2 p^{\prime}-1\right)-(1-\eta) \mu_{c o}\right)\right\}\right]+\left(1-p^{\prime}\right)^{2}[0] .
$$

Simplifying gives Equation (7) in the text.

\section{References}

Agarwal, R., Echambadi, R., Franco, A.M. and Sarkar, M. (2004): "Knowledge Transfer Through Inheritance: SpinOut Generation, Development, and Survival", Academy of Management Journal, Vol. 47, pp. 501-522.

Akerlof, G.A. and Kranton, R.E. (2005): "Identity and the Economics of Organizations", Journal of Economic Perspectives, Vol. 19, pp. 9-32.

Albanese, R. and van Fleet, D.D. (1985): "Rational Behavior in Groups: The Free-Riding Tendency", Academy of Management Review, Vol. 10, pp. 244-255.

Aronson, E., Wilson, T.D. and Akert, R.M. (2002): Social Psychology, Upper Saddle River, NJ: Prentice-Hall.

Arrow, K.J. (1974): The Limits of Organization, New York: W. W. Norton \& Company.

Audretsch, D.B. and Mahmood, T. (1994): "Firm Selection and Industry Evolution: The Post-Entry Performance of New Firms", Journal of Evolutionary Economics, Vol. 4, pp. 243-260.

Barney, J.B. (1986): "Organizational Culture: Can It Be a Source of Sustained Competitive Advantage?", The Academy of Management Review, Vol. 11, pp. 656-665.

Bolton, G.E. and Ockenfels, A. (2000): "ERC: A Theory of Equity, Reciprocity, and Competition", American Economic Review, Vol. 90, pp. 166-193.

Boone, C., Carroll, G.R. and van Witteloostuijn, A. (2004): "Size, Differentiation and the Performance of Dutch Daily Newspapers", Industrial and Corporate Change, Vol. 13, pp. 117-148.

Boyd, R. and Richerson, P.J. (1980): "Sociobiology, Culture and Economic Theory", Journal of Economic Behavior \& Organization, Vol. 1, pp. 97-121.

Boyd, R. and Richerson, P.J. (1985): Culture and the Evolutionary Process, Chicago: University of Chicago Press.

Boyd, R. and Richerson, P.J. (2002): "Group Beneficial Norms Can Spread Rapidly in a Structured Population", Journal of Theoretical Biology, Vol. 215, pp. 287-296.

Brewer, M.B. and Kramer, R.M. (1986): "Choice Behavior in Social Dilemmas: Effects of Social Identity, Group Size, and Decision Framing", Journal of Personality and Social Psychology, Vol. 50, pp. 543-549.

Brittain, J.W. and Freeman, J. (1986): "Entrepreneurship in the Semiconductor Industry", Mimeo.

Buenstorf, G. (2009): "Opportunity Spin-Offs and Necessity Spin-Offs", International Journal of Entrepreneurial Venturing, Vol. 1, pp. 22-40. 
Buenstorf, G. and Klepper, S. (2009): "Heritage and Agglomeration: The Akron Tyre Cluster Revisited", The Economic Journal, Vol. 119, pp. 705-733.

Cabral, L.M. and Wang, Z. (2009): "Spin-Offs: Theory and Evidence from the Early U.S. Automobile Industry", The Federal Reserve Bank of Kansas City, RWP 08-15, pp. 1-29.

Card, D., Mas, A. and Rothstein, J. (2008): "Tipping and the Dynamics of Segregation", Quarterly Journal of Economics, Vol. 123, pp. 177-218.

Cavalli-Sforza, L.L. and Feldman, M.W. (1981): Cultural Transmission and Evolution: A Quantitative Approach, Princeton: Princeton University Press.

Chatterji, A.K. (2009): "Spawned With a Silver Spoon? Entrepreneurial Performance and Innovation in the Medical Device Industry", Strategic Management Journal, Vol. 30, pp. 185-206.

Christensen, C.M. (1993): "The Rigid Disk Drive Industry: A History of Commercial and Technological Turbulence", Business History Review, Vol. 67, pp. 531-588.

Churchill, N.C. and Lewis, V.L. (1983): "The Five Stages of Small Business Growth", Harvard Business Review, 61, pp. 30-50.

Cialdini, R.B. and Goldstein, N.J. (2004): "Social Influence: Compliance and Conformity", Annual Review of Psychology, Vol. 55, pp. 591-621.

Cooter, R. and Eisenberg, M.A. (2001): "Fairness, Character, and Efficiency in Firms", University of Pennsylvania Law Review, Vol. 149, pp. 1717-1733.

Cordes, C., Richerson, P.J., McElreath, R. and Strimling, P. (2008): "A Naturalistic Approach to the Theory of the Firm: The Role of Cooperation and Cultural Evolution", Journal of Economic Behavior \& Organization, Vol. 68, pp. 125-139.

Cordes, C., Richerson, P.J., McElreath, R. and Strimling, P. (2011): "How Does Opportunistic Behavior Influence Firm Size? An Evolutionary Approach to Organizational Behavior", Journal of Institutional Economics, Vol. 7, pp. 1-21.

Cordes, C., Richerson, P.J. and Schwesinger, G. (2010): "How Corporate Cultures Coevolve with the Business Environment: The Case of Firm Growth Crises and Industry Evolution", Journal of Economic Behavior \& Organization, Vol. 76, pp. 465-480.

Crémer, J. (1993): "Corporate Culture and Shared Knowledge", Industrial and Corporate Change, Vol. 2, pp. 351386.

Dahl, M.S. and Reichstein, T. (2007): "Are You Experienced? Prior Experience and the Survival of New Organizations", Industry and Innovation, Vol. 14, pp. 497-511.

Deal, T.E. and Kennedy, A.A. (1982): Corporate Cultures: The Rites and Rituals of Corporate Life, Reading, Mass.: Addison-Wesley.

Deckop, J.R., Mangel, R. and Cirka, C.C. (1999): "Getting More than You Pay for: Organizational Citizenship Behavior and Pay-for-Performance Plans", The Academy of Management Journal, Vol. 42, pp. 420-428.

Elfenbein, D.W., Hamilton, B.H. and Zenger, T.R. (2010): "The Small Firm Effect and the Entrepreneurial Spawning of Scientists and Engineers", Management Science, Vol. 56, pp. 659-681.

Ellis, S., Drori, I. and Shapira, Z. (2008): "Genealogy as Evolutionary Dynamics", Working Paper, pp. 1-51.

Enzle, M.E. and Anderson, S.C. (1993): "Surveillant Intentions and Intrinsic Motivation", Journal of Personality and Social Psychology, Vol. 64, pp. 257-266.

Eriksson, T. and Kuhn, J.M. (2006): "Firm Spin-Offs in Denmark, 1981-200 - Patterns of Entry and Exit", International Journal of Industrial Organization, Vol. 24, pp. 1021-1040.

Fehr, E. and Gächter, S. (2000): "Cooperation and Punishment in Public Goods Experiments", American Economic Review, Vol. 90, pp. 980-994.

Forsyth, D.R. (2006): Group Dynamics, Belmont: Thomson Wadsworth.

Franco, A.M. and Filson, D. (2006): "Spin-Outs: Knowledge Diffusion Through Employee Mobility", RAND Journal of Economics, Vol. 37, pp. 841-860.

Garvin, D.A. (1983): "Spin-Offs and the New Firm Formation Process", California Management Review, Vol. 25, pp. 3-20.

Ghoshal, S. and Moran, P. (1996): "Bad for Practice: A Critique of the Transaction Cost Theory", Academy of Management Review, Vol. 21, pp. 13-47.

Gittell, J.H. (2000): "Organizing Work to Support Relational Co-Ordination", International Journal of Human Resource Management, Vol. 11, pp. 517-539.

Gladwell, M. (2000): The Tipping Point, Boston: Little, Brown and Company.

Gooding, R.Z. and Wagner III, J.A. (1985): "A Meta-Analytic Review of the Relationship between Size and Performance: The Productivity and Efficiency of Organizations and their Subunits", Administrative Science Quarterly, Vol. 30, pp. 462-481. 
Greiner, L.E. (1998): "Evolution and Revolution as Organizations Grow", Harvard Business Review, Vol. 76, pp. 5567.

Grofman, B. (1974): "Helping Behavior and Group Size: Some Exploratory Stochastic Models", Behavioral Science, Vol. 19, pp. 219-224.

Güth, W. and van Damme, E. (1998): "Information, Strategic Behavior, and Fairness in Ultimatum Bargaining: An Experimental Study", Journal of Mathematical Psychology, Vol. 42, pp. 227-247.

Hannan, M.T. and Freeman, J. (1977): "The Population Ecology of Organizations", American Journal of Sociology, Vol. 82, pp. 929-964.

Harrington Jr., J.E. (1999): "Rigidity of Social Systems", Journal of Political Economy, Vol. 107, pp. 40-64.

Henrich, J. (2001): "Cultural Transmission and the Diffusion of Innovations: Adoption Dynamics Indicate that Biased Cultural Transmission is the Predominant Force in Behavioral Change", American Anthropologist, Vol. 103, pp. 992-1013.

Henrich, J. (2004): "Cultural Group Selection, Coevolutionary Processes and Large-scale Cooperation", Journal of Economic Behavior \& Organization, Vol. 53, pp. 3-35.

Henrich, J. and Boyd, R. (2002): "On Modeling Cognition and Culture", Journal of Cognition and Culture, Vol. 2, pp. 87-112.

Henrich, J., Boyd, R., Bowles, S., Camerer, C., Fehr, E., Gintis, H. and McElreath, R. (2001): "In Search of Homo Economicus: Behavioral Experiments in 15 Small-Scale Societies", American Economic Review, Vol. 91, pp. 73-78.

Henrich, J. and Gil-White, F.J. (2001): "The Evolution of Prestige: Freely Conferred Deference as a Mechanism for Enhancing the Benefits of Cultural Transmission", Evolution and Human Behavior, Vol. 22, pp. 165-196.

Hermalin, B.E. (2001): "Economics and Corporate Culture", in: Cooper, C.L., Cartwright, S. and Earley, C.P. (eds.), The International Handbook of Organizational Culture and Climate, Chichester: Wiley, pp. 217-261.

Higgins, M.C. (2005): Career Imprints: Creating Leaders Across an Industry, San Francisco: Jossey-Bass.

Jovanovic, B. and MacDonald, G.M. (1994): "The Life Cycle of a Competitive Industry", Journal of Political Economy, Vol. 102, pp. 322-347.

Kameda, T. and Diasuke, N. (2002): "Cost-benefit Analysis of Social/Cultural Learning in a Nonstationary Uncertain Environment: An Evolutionary Simulation and an Experiment with Human Subjects", Evolution and Human Behavior, Vol. 23, pp. 373-393.

Katz, D. (1964): "The Motivational Basis of Organizational Behavior", Behavioral Science, Vol. 9, pp. 131-146.

Kenney, M. and von Burg, U. (1999): "Technology, Entrepreneurship and Path Dependence: Industrial Clustering in Silicon Valley and Route 128", Industrial and Corporate Change, Vol. 8, pp. 67-103.

Kerr, N.L. (1989): "Illusions of Efficacy: The Effects of Group Size on Perceived Efficacy in Social Dilemmas", Journal of Experimental Social Psychology, Vol. 25, pp. 287-313.

Klepper, S. (1996): "Entry, Exit, Growth, and Innovation over the Product Life Cycle", American Economic Review, Vol. 86, pp. 562-583.

Klepper, S. (2002): "The Capabilities of New Firms and the Evolution of the US Automobile Industry", Industrial and Corporate Change, Vol. 11, pp. 645-666.

Klepper, S. (2009): "Spinoffs: A Review and Synthesis", European Management Review, Vol. 6, pp. 159-171.

Klepper, S. and Sleeper, S.B. (2005): "Entry by Spinoffs", Management Science, Vol. 51, pp. 1291-1306.

Klepper, S. and Thompson, P. (2010): "Disagreements and Intra-Industry Spinoffs", International Journal of Industrial Organization, Vol. 28, pp. 526-538.

Kosfeld, M. and von Siemens, F.A. (2011): "Competition, Cooperation, and Corporate Culture", RAND Journal of Economics, Vol. 42, pp. 23-43.

Kotter, J.P. and Heskett, J.L. (1992): Corporate Culture and Performance, New York: Free Press.

Labov, W. (2001): Principles of Linguistic Change: Social Factors, Oxford: Blackwell.

Langlois, R.N. (1998): "Personal Capitalism as Charismatic Authority: The Organizational Economics of a Weberian Concept", Industrial and Corporate Change, Vol. 7, pp. 195-213.

Levine, J.M. and Moreland, R.L. (1990): "Progress in Small Group Research", Annual Review of Psychology, Vol. 41, pp. 585-634.

Levine, J.M. and Moreland, R.L. (1998): "Small Groups", in: Gilbert, D. T., Fiske, S. T. and Lindzey, G. (eds.), The Handbook of Social Psychology, Boston: McGraw-Hill, pp. 415-469.

March, J.G. (1991): "Exploration and Exploitation in Organizational Learning", Organization Science, Vol. 2, pp. 71-87.

Markham, S.E., Dansereau, F. Jr. and Alutto, J.A. (1982): "Group Size and Absenteeism Rates: A Longitudinal Analysis", Academy of Management Journal, Vol. 25, pp. 921-927.

Marlowe, F.W. (2005): "Hunter-Gatherers and Human Evolution", Evolutionary Anthropology, Vol. 14, pp. 54-67. 
McKendrick, D.G., Wade, J.B. and Jaffee, J. (2009): "A Good Riddance? Spin-Offs and the Technological Performance of Parent Firms", Organization Science, Vol. 20, pp. 979-992.

Milgram, S. (1974): Obedience to Authority: An Experimental View, New York: Harper\&Row.

Moore, G. and Davis, K. (2004): "Learning the Silicon Valley Way", in: Bresnahan, T.F. and Gambardella, A. (eds.), Building High-Tech Clusters: Silicon Valley and Beyond, Cambridge: Cambridge University Press, pp. 739.

Mukhopadhaya, K. (2003): "Jury Size and the Free Rider Problem", Journal of Law, Economics, \& Organization, Vol. 19, pp. 24-44.

Norenzayan, A. and Heine, S.J. (2005): "Psychological Universals: What Are They and How Can We Know?", Psychological Bulletin, Vol. 131, pp. 763-784.

Olson, M. (1994): The Logic of Collective Action, Cambridge, MA: Harvard University Press.

Ostrom, E. (2009): "A General Framework for Analyzing the Sustainability of Social-Ecological Systems", Science, Vol. 325, pp. 419-422.

Pakes, A. and Nitzan, S. (1983): "Optimum Contracts for Research Personnel, Research Employment, and the Establishment of "Rival" Enterprises", Journal of Labor Economics, Vol. 1, pp. 345-365.

Pratten, C.F. (1971): Economies of Scale in Manufacturing Industry, Cambridge: Cambridge University Press.

Richerson, P.J. and Boyd, R. (2005): Not by Genes Alone: How Culture Transformed Human Evolution, Chicago: The University of Chicago Press.

Rob, R. and Zemsky, P. (2002): "Social Capital, Corporate Culture, and Incentive Intensity", RAND Journal of Economics, Vol. 33, pp. 243-257.

Rogers, E.M. (1983): Diffusion of Innovations, New York: Free Press.

Rubin, P.H. (1982): "Evolved Ethics and Efficient Ethics", Journal of Economic Behavior \& Organization, Vol. 3, pp. 161-174.

Schein, E.H. (1992): Organizational Culture and Leadership, San Francisco: Jossey-Bass Publishers.

Schelling, T.C. (1972): "The Process of Residential Segregation: Neighborhood Tipping", in: Pascal, A.H. (ed.), Racial Discrimination in Economic Life, Lexington, MA: Lexington Books, pp. 157-184.

Schumpeter, J.A. (1939): Business Cycles, New York: McGraw-Hill.

Sørensen, J.B. (2007): "Bureaucracy and Entrepreneurship: Workplace Effects on Entrepreneurial Entry", Administrative Science Quarterly, Vol. 52, pp. 387-412.

Spoor, J.R. and Kelly, J.R. (2004): "The Evolutionary Significance of Affect in Groups: Communication and Group Bonding", Group Processes \& Intergroup Relations, Vol. 7, pp. 398-412.

Stuart, T.E. and Sorenson, O. (2003): "Liquidity Events and the Geographic Distribution of Entrepreneurial Activity", Administrative Science Quarterly, Vol. 48, pp. 175-201.

Teece, D.J., Pisano, G. and Shuen, A. (1997): "Dynamic Capabilities and Strategic Management", Strategic Management Journal, Vol. 18, pp. 509-533.

Thompson, J.D. (1967): Organizations in Action, New York: McGraw-Hill.

Tichy, N.M. (1983): Managing Strategic Change: Technical, Political, and Cultural Dynamics, New York: Wiley.

van den Bergh, J.C.J.M. and Gowdy, J.M. (2009): "A Group Selection Perspective on Economic Behavior, Institutions, and Organizations", Journal of Economic Behavior \& Organization, Vol. 72, pp. 1-20.

Van den Steen, E. (2010): "On the Origin of Shared Beliefs (and Corporate Culture)", RAND Journal of Economics, Vol. 41, pp. 617-648.

Wagner III, J.A. (1995): "Studies of Individualism-Collectivism: Effects on Cooperation in Groups", Academy of Management Journal, Vol. 38, pp. 152-172.

Williamson, O.E. (2002): "The Theory of the Firm as Governance Structure: From Choice to Contract", Journal of Economic Perspectives, Vol. 16, pp. 171-195.

Witt, U. (1998): "Imagination and Leadership - The Neglected Dimension of an Evolutionary Theory of the Firm", Journal of Economic Behavior \& Organization, Vol. 35, pp. 161-177.

Witt, U. (2000): "Changing Cognitive Frames - Changing Organizational Forms: An Entrepreneurial Theory of Organizational Development", Industrial and Corporate Change, Vol. 9, pp. 733-755.

Witt, U. (2007): "Firms as Realizations of Entrepreneurial Visions", Journal of Management Studies, Vol. 44, pp. 1125-1140. 